\title{
Bacteriological Assessment for Iced Sugarcane Juice in Korba, Chhattisgarh, India
}

\author{
Shweta Sao and Rajshree Singh* \\ Dr C.V. Raman University, Bilaspur, India \\ *Corresponding Author: Rajshree Singh, Dr C.V. Raman University, Bilaspur, India.
}

Received: April 27, 2019; Published: July 02, 2019

DOI: $10.31080 /$ ASMI.2019.02.0289

\begin{abstract}
Sugarcane juice is a common man's refreshing beverage that was extensively consumed during hot summers, among the all population group and has been great concern of hygienic measure as it was poorly implemented by street vendors and hawker. The present study aims to evaluate the quality of ice used in the sugarcane juice in different place of Korba, C.G. Ice samples collected were found to be contaminated by many pathogenic and non-pathogenic bacteria with very high bacterial load $\left(5 \times 10^{5}-6 \times 10^{7} \mathrm{CFU} / \mathrm{ml}\right)$ indicating a serious health concern for the people consuming it, in our study we have identified Leclercia adecarboxylata, Citrobacter freundii and Escherichia hermannii, which represents source of microbial contaminant from where the ice were bought are either from hospital morgue or from cold storage where meat and fishes were stored.
\end{abstract}

Keywords: Sugarcane Juice; Bacterial load; Ice; Coliform

\section{Introduction}

Sugarcane juice is a common man's refreshing beverage extensively consumed during hot summers that not only quenches the trust but also invigorates as well. Its unique properties to giving tolerance against the heat, availability at very cheaper cost and ubiquitous distribution makes it very popular drink among all class of people in every part of India. Sugarcane juice was extracted by crushing the sugarcane between the roller drums and served with or without ice, and it majorly composed of approximately $80 \%$ water and $20 \%$ total dissolved solids, $17 \%$ saccharose, $0.4 \%$ glucose and $0.2 \%$ fructose, traces of nitrogenous substances such as organic acids, vitamins $\mathrm{A}$, B-complex, and $\mathrm{C}$ and also minerals such as iron, calcium, potassium, sodium and magnesium $[1,2]$.

Sugarcane juice was majorly contaminated by spoilage microorganisms which primary causes chemical, physical and sensory deterioration of the drink. Significant variation in $\mathrm{pH}$ of the juice leads to accelerated microbial spoilage [3], the source of microbial contamination was supposed to be the raw material used such as unhygienic storage and extraction places, improper handling of sugarcane, knives, press, clothes, contact surface, ice, vendor's hands and air born contamination, causing various infectious diseases such as vomiting, nausea, abdominal cramps, typhoid, diarrhea etc $[3,4]$, there had been good number of cases reported for occurrence of food borne disease such as Vibrio cholerae was considered to be organisms responsible for causing serious epidemic in Pune in 1991 due to contaminated sugarcane juice (Kusumaningrum, 2004). In-order to ensure microbiologically safe juice there must be strong and regular monitoring of processing of juice as poor hygienic conditions were predominant in the majority of places where sugarcane juice was sold [5]. It was observed that in room temperature sugarcane juice contains mainly mesophilic bacteria, whereas in refrigerated condition the growth is possible mainly due to psychrophilic bacteria. Most predominant species that expressed in juice and mixed juice were Streptococcus sp. Occasionally, lactobacillus fermentum, Leuconostoc mesenteroides and Erwinia herbicola were also predominant. Studies also reveal the presence of Bacillus sps. Streptococcus sps., and lactobacillus cellubiosus these are detrimental to sucrose present in the sugar cane juice. In our studies presence of Leclercia adecarboxylata, Citrobacter freundii and Escherichia hermannii was of great concern due to their source of origin indicates that the Ice used in sugarcane juice were bought from Morgue or from cold storage where meats were preserved. 


\section{Materials and Methods}

Description of sampling sites

Samples of analysis i.e ICE which were used in sugarcane juice collected from 6 different locations in Korba among them 5 were from street sugarcane juice wander from transport nagar, and one sample from street sugarcane juice wander from Darri Road, Korba. Samples were collected in four replicates aseptically in sterile glass bottles, labeled properly and transported to the laboratory for analysis. Aliquots of the samples were used for selective isolation of different bacterial species based on standard microbiological procedures.

Microbiological analysis of Ice

Total plate count (TPC)

The samples were opened in a laminar airflow chamber under all aseptic measures. Total Viable Count was determined by pour plate method. Serial dilutions (10:1, 10:2, 10:3 and 10:4) were made from the ice samples and aliquots of $1 \mathrm{ml}$ were added to each duplicate Petri dish. Plate count agar (PCA) was added to each Petri dish and incubated at $35^{\circ} \mathrm{C}$ for 48 hours \pm 2 , after incubation colonies were counted by colony counter and result was expressed as $\mathrm{CFU} / \mathrm{ml}[6,7]$.

Total coliform bacteria/Fecal coliform bacteria

Most Probable Number (MPN) test was performed to assess the total Coliforms count pollution level in the selected area for total Coliform count and determined by multiple tube fermentation technique $[6,7]$. The technique involves three successive steps namely, presumptive test, confirmatory test and completed test. Total coliform and fecal coliform were calculated from MPN index table from a serial dilution of soil suspensions. The microbial colonies were counted in the three replica plates and the average values were calculated. The populations of microorganisms were considered from the number of microbes multiplied by the dilution factor for each sample.

\section{Escherichia coli (E. coli)}

EMB Agar was used for the enumeration of E. coli. All the tubes of E.C. broth showing gas were subculture by streaking on EMB agar plates and incubated at $35^{\circ} \mathrm{C}$ for $18-24 \mathrm{hrs}$. Positive plates contained typical colonies with green metallic sheen were inoculated on PCA slants (plate count agar) and incubated at $35^{\circ} \mathrm{C}$ for 18-24 hrs and identified biochemically [6,7].
Pure culture of bacteria species

Pure culture of bacterial species from water samples were obtained by serial dilution methods recommended by Harley Prescott, 2002. The isolated bacterial strains were cultured in nutrient agar medium (Hi Media Laboratory, India). Serial dilution of the samples was made using sterile distilled water. $0.1 \mathrm{ml}$ of this dilution was inoculated on nutrient agar and incubated at $37^{\circ} \mathrm{C}$ for $24 \mathrm{hrs}$. Pure cultures were isolated and sub-cultured twice in the same medium at $37^{\circ} \mathrm{C}$. Pure cultures were subjected to biochemical identification tests its identification and characterization following the methods described in Bergey's Manual of Systematic Bacteriology. The bacteria that were picked to create anti bio-grams were streaked on to nutrient agar slants to make sample cultures and for PCR purpose.

\section{Biochemical characterization of the isolates}

The species were characterized by biochemical tests performed as per standard Microbiological methods [8], including Gelatin hydrolysis test, Starch hydrolysis test, Casein hydrolysis test, Catalase activity test, Glucose Fermentation test, Citrate utilization test, Nitrate reduction test, Oxidase Test, VP -Voges-Proskauer Test ("Vi"), Urease Test. Species identification was also confirmed by VITEK-2C (Biomerieux, France).

Antibiotic sensitivity

Antibiotic sensitivity of isolated microorganisms towards Ticarcillin. Piperacillin, Clavulanic acid, Ceftazidine, Cefoperazone/sulbactam, cefepime, aztreonam, doripenem, imipenam, meropenam, amikacin, gentamicin, ciprofloxacin, levofloxacin, minocyclin, tigercyclin, colistin, trimethoprim/sulpamethoxazole, were testing in VITEK-2C (Biomerieux, France) as per manufacturers instruction.

\section{Results}

25 samples used on sugarcane juice vender were collected from 5 different places in Korba, among them 4 were from transport nagar, and one sample was from Darri Road, samples were analyzed for total plate count, total coliform count and no of $E$. coli present. For the safety of public health, it was crucial to monitor the measure the complete microbial evaluation for the safe drinking purposes [9], our results showed that in all the localities the sugar cane juices remained hygienically poor based on high bacterial load (total plate count, total coliform count, total fecal coliform count, E. Coli count). It was observed that overall count were quite high and almost same everywhere (Table 1 ) represents that samples were equally conta- 
minated and cannot be used for safe drinking purposes. The presence of coliform bacteria may also be due to the contaminated water used in ice. It was observed that significant bacterial species were present in the ice sample those are capable enough to cause severe outbreak and their origin was animal and mostly animal specifically from human diseases.

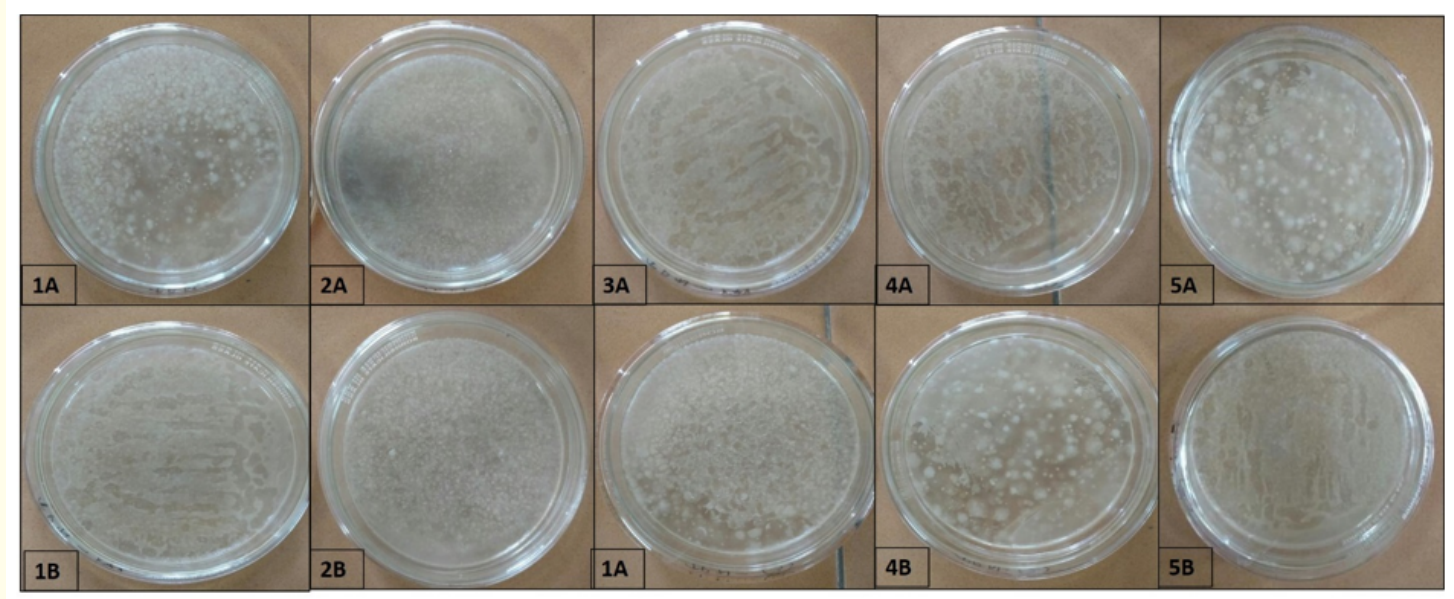

Figure 1: Bacterial colony isolated from ice samples collected from different locations of Korba.

\begin{tabular}{|l|c|c|c|c|}
\hline Site of collection & $\begin{array}{c}\text { Total plate count } \\
\text { (cfu/ml) }\end{array}$ & $\begin{array}{c}\text { Total coliform } \\
\text { count (MPN/ml) }\end{array}$ & $\begin{array}{c}\text { Total fecal coliform } \\
\text { count (MPN/ml) }\end{array}$ & E. coli \\
\hline Darri Nala & $5 \times 10^{5}$ & 110 & 85 & + +ve \\
\hline Transport Nagar A & $6 \times 10^{7}$ & 155 & 100 & + +ve \\
\hline Transport Nagar B & $4 \times 10^{7}$ & 150 & 95 & $+\mathrm{ve}$ \\
\hline Transport Nagar C & $5 \times 10^{7}$ & 149 & 93 & $+\mathrm{ve}$ \\
\hline Transport Nagar D & $3 \times 10^{6}$ & 140 & 90 & $+\mathrm{ve}$ \\
\hline
\end{tabular}

Table 1: Table representing bacterial load, total plate and coliform count, fecal count, and presence of $E$. coli.

In our study, we have isolated Escherichia hermannii, Leclercia adecarboxylata, and Citrobacter freundii. Leclercia adecarboxylata, also identified as Escherichia adecarboxylata (motile gram negative rod shaped bacteria) found to be most profoundly distributed in nature and had been isolated from food, water, and other environmental sources as well as from various clinical specimens, including blood, faces, sputum, urine, and wound pus [10]. It was also reported in many cases such as immuno compromised individuals with infections of a polymicrobial nature [11], trauma patient as rare pathogen in endocarditis [12], catheter-related bacteremia [13], bacteremia and cellulitis in children suffering from leukemia [14-16].
Citrobacter freundii, (facultative anaerobic gram-negative rod shaped bacteria of Enterobacteriaceae family which was ubiquitous in distribution and commonly found in soil, water, sewage, food and represents approximately 29\% of all opportunistic infections in the intestinal tracts of animals and humans [17], It is known to cause variety of nosocomial infections of the respiratory tract, urinary tract, blood and several other normally sterile sites in patients [17], it was also found to associated with neonatal meningitis and brain abscess [18] with very high morbidity.

Escherichia hermannii (Gram-negative, rod-shaped bacterium), was reported as the sole pathogen in a catheter-related bloodstream infection, it was also has been isolated from human 
wounds [19], eye infections, blood [20-22], it was also found that E. hermannii is inherently resistant to penicillin, ampicillin, and carbenicillin but sensitive to other $\beta$-lactam antibiotics (cephalosporins, carbapenems, and monobactam) [23-25].

\section{Conclusions}

In the Present study presence of heavy bacterial contaminant in ice used in preparation of sugarcane juice, presence of organisms such as Escherichia hermannii, Leclercia adecarboxylata, and Citrobacter freundii represents the Ice used were bought from the places such as morgue, meat house or meat cold storage, which were responsible to cause critical health problem.

\section{Bibliography}

1. Stupiello JP. “The sugarcane as feed material”. Fundação Cargill, Campinas 2 (1987): 761-804.

2. Carvalho LR., et al. "Evaluation of microbiological quality of cane stocks traded in the center of Itabuna-BA and production practices and hygiene of their handlers". Revista Baiana de Saúde Pública 31 (2007): 238-245.

3. Jeffrey CP. “Alcamo's Fundamentals of Microbiology, 7th ed., Sudbury, UK". (2004): 309.

4. Imran P., et al. "Baking quality of wheat flour cookies supplemented with fiber from different sources". Pakistan Journal of Food Sciences 18 (2008): 1-8.

5. APHA. Compendium of Methods for the Microbiological Examination of Foods, American Public Health Association 4th Edition Washington DC (2001).

6. Javid A., et al. "Comparative Microbiological Quality Evaluation of Un-Branded and Branded Juices of Street Vended Sold in Retail Outlet of Peshawar City". American-Eurasian Journal of Agricultural and Environmental Sciences 13.3 (2013): 1155-1159.

7. Javid A., et al. "Bacteriological Quality Analysis of Drinking Water of Rural Areas of Peshawar, Pakistan". American-Eurasian Journal of Agricultural and Environmental Sciences 13.9 (2013a): 1202-1206.

8. Cappuccino J and Sherman N. "Microbiology-A laboratory manual 8th Edition". Benjamin-Cummings Publisher (2007).

9. Alonso Pippo W., et al. "Agroindustry sugarcane residues disposal: The trends of their conversion into energy carriers in Cuba". Waste Management 27 (2007): 869-885.
10. Stock I., et al. "Natural antimicrobial susceptibility patterns and biochemical profiles of Leclercia adecarboxylata strains". Clinical Microbiology Infection 10 (2004): 724-733.

11. Forrester JD., et al. "Leclercia adecarboxylata bacteremia in a trauma patient: case report and review of the literature". Surgical Infections (Larchmt) 13 (2012): 63-66.

12. Lee B., et al. "A case of Leclercia adecarboxylata endocarditis in a woman with endometrial cancer". The American Journal of the Medical Sciences 337 (2009): 146-147.

13. Shin., et al. "Catheter-related bacteremia caused by multidrugresistant Leclercia adecarboxylata in a patient with breast cancer". Journal of Clinical Microbiology 50 (2012): 3129-3132.

14. Longhurst CA., et al. "Isolation of Leclercia adecarboxylata from an infant with acute lymphoblastic leukemia". Clinical Infectious Diseases 32 (2001): 1659.

15. Shah A., et al. "Leclercia adecarboxylata cellulitis in a child with acute lymphoblastic leukemia". Pediatric Dermatology 28 (2011): 162-164.

16. Tam V and NAYAK S. "Isolation of Leclercia adecarboxylata from a wound infection after exposure to hurricane-related floodwater". BMJ Case Report (2012).

17. Whalen JG., et al. "Spontaneous Citrobacter freundii infection in an immunocompetent patient". Archives of dermatology 143.1 (2007): 124-125.

18. JOAQUIN A., et al. "Neonatal meningitis and bilateral cerebellar abscesses due to Citrobacter freundii". Pediatric Neurosurgery 17 (1991): 23-24.

19. Poulou A., et al. "Escherichia hermannii as the sole isolate from a patient with purulent conjunctivitis". Journal of Clinical Microbiology 46.11 (2008): 3848-3849.

20. Dahl KM., et al. "Escherichia hermannii infection of a cephalohematoma: case report, review of the literature, and description of a novel invasive pathogen". Clinical Infectious Diseases 35.9 (2002): e96-e98.

21. Tong YQ., et al. "Pyelonephritis caused solely by Escherichia hermanii". Jundishapur Journal of Microbiology 7.5 (2014): e18138.

22. Choudhury S and SEET C. "Escherichia hermannii bloodstream infection in a long-term haemodialysis patient". Pathology 45.5 (2013): 531. 
23. Rice Ew., et al. "Serological cross-reactions between Escherichia coli 0157 and other species of the genus Escherichia". Journal of Clinical Microbiology 30.5 (1992): 1315-1316.

24. Karmakar R., et al. "Effect of pretreatments on physico-chemical characteristics of sugarcane juice". Sugar Technology 13.1 (2011): 47-50.

25. Lee NY., et al. "Hickman catheter-associated bacteremia by Leclercia adecarboxylata and Escherichia hermannii: A case report". Korean Journal of Infectious Diseases 31 (1999): 167170.

Volume 2 Issue 8 August 2019

(C) All rights are reserved by Shweta Sao and Rajshree Singh. 